\title{
Toward a biocultural theory of avoided extinction
}

\author{
Richard J. Ladle \& Paul Jepson \\ Biodiversity Research Group, Oxford University Centre for the Environment, University of Oxford, UK
}

\begin{abstract}
Keywords
Advocacy; extinction; interdisciplinary; local extinction; social science.

\section{Correspondence}

Richard J. Ladle, Oxford University Centre for the Environment, Dyson Perrins Building, South Parks Road, Oxford OX1 3PS, UK. Tel: +44 (0) 1865285 184; fax: +44 (0) 1865275885.

E-mail: richard.ladle@ouce.ox.ac.uk
\end{abstract}

Received: 27 April 2008; accepted 5 May 2008.

doi: 10.1111/j.1755-263X.2008.00016.x

\begin{abstract}
Avoiding extinction is one of the main aims of the global conservation movement and its study has historically been dominated by ecological thinking about the consequences of small population size and the identification of the proximate causes of population decline. Here we argue that any successful theorization on avoiding extinction has to look beyond ecology to incorporate the behavior of conservationists, conservation organizations, and other societal actors. We develop a "biocultural" framework based on a typology of extinction that emphasizes the different meanings and power of the term and discuss how these might inform more effective global conservation policy and practice. Seen through a biocultural perspective, we argue that extinction will only be effectively reduced when scientific evidence, cultural frames, institutional frameworks, and organizational interests align.
\end{abstract}

\section{Introduction}

Extinction is a key concept in conservation that has been used to mobilize support, legitimize policy and determine the geographic foci of action. Theory about reducing the probability of species' extinction within Conservation $\mathrm{Bi}$ ology has so far been characterized by two main strands: first, the small population paradigm, which posits that as populations become small they be increasingly subject to positive feedback, loops among biotic and abiotic processes leading to an "extinction vortex" (Gilpin \& Soulé 1986; Fagan \& Holmes 2006). Second, the declining population paradigm that posits that population declines have identifiable causes and, with considered interventions, can be defused (Caughley 1994; Norris 2004). These two paradigms have been reified into a set of categories and criteria that assign a probability of extinction to a species within time-scales meaningful for conservation (Mace \& Lande 1991, IUCN 1994).

However, as Caughley (1994) presciently pointed out in his influential review, there is little evidence of these paradigms intersecting to "enlarge our idea of what is possible" (p 240) in terms of a theory of extinction, or more usefully, a theory of avoided extinction. Furthermore, despite considerable methodological and predictive advances within both these paradigms, we seem little fur- ther on with such a theory. Here we suggest a different tack. We argue that "extinction" is a signifier that has several distinct meanings (and therefore powers) in different contexts. Because "saving" species from extinction is a fundamental tenet of conservation, and because this requires social consent and the engagement of institutions and organizations, it necessarily follows that advances in the theorization of avoided extinction need to recognize explicitly the multiple meanings of the term and the power of each in the social processes of framing, mobilizing, and legitimizing collective action. In this essay, we first develop a new socio-cultural typology of extinction that better reflects the multiple ways in which extinction is used and has agency within conservation. In the second part of the essay, we examine the various uses of extinction by conservation actors and organizations and argue that only when the cultural context of extinction is better understood will human-induced extinction be better avoided

\section{A new typology of extinction}

Traditionally, extinction has been viewed as the logical end point of the process of population decline. In other words, it is the point on the graph where the population size curve meets the $\mathrm{x}$-axis and terminates abruptly. The 
IUCN (1994, 2001) defines a species as extinct if "there is no reasonable doubt that the last individual has died". However, whilst this clearly defines the state of being extinct it falls far short of capturing the implications and meaning of the noun "extinction". Our typology is primarily based on different degrees of scientific certainty associated with the disappearance of a species and the potential for its re-emergence at some point in the future. As we will argue, these two dimensions affect the social influence and power of the term and therefore its uses and impact in conservation advocacy.

Perhaps the prevalent meaning of extinction in advocacy, but the least well empirically documented, are extinctions inferred from the Linnean shortfall in conservation biogeography. This enables extinctions of as yet undiscovered and/or undescribed taxa to be extrapolated from data on the rate of new species discovery, the species-area curve, and rates of habitat loss. This "Linnean" meaning of extinction (Table 1, Figure 1A) generates startling and worrying figures. For example, E. O. Wilson's "conservative" prediction of approximately 27,000 species going extinct every year based on the rate of tropical deforestation (Wilson 1991, p 268).

Our second type of extinction, we term "Wallacean extinctions" (Table 1, Figure 1B) after the Wallacean Shortfall in biogeography (Lomolino 2004; Whittaker et al. 2005), a term used to describe inadequacies in our knowledge of the global, regional, and even local distribution of many species. Such a lack of information can lead to species erroneously being classed as extinct or threatened with extinction when undiscovered populations are still extant.

Our third category of extinction we term "Phoenix extinctions" (Table 1, Figure $1 \mathrm{C}$ ). These are species that have become extinct under the IUCN definition above, but have been (or have the potential to be) resurrected from the ashes of extinction through human ingenuity, imagination, or both. Phoenix extinctions take at least two forms. The first is based on the idea that some species have not become extinct but rather they have been transformed by human action. A fascinating example of this sub-type is happening in Holland where a group of forward thinking government conservationists has successfully managed back-bred domesticated cattle to fashion a wild-acting replicate of the Auroch (Bos primigenius). The term Phoenix extinction might also be applied to species such as the plains bison (Bison bison) that was subject to extensive hybridization with domesticate cattle during the late 1800s and early 1900s when the population size had fallen to critical levels (Freese et al. 2007). Similarly, attempts to create a quagga-like animal by selectively breeding zebra may also fall into this category.

The second form of phoenix extinction is the technological solution of recreating species from genetic material stored in gene banks or extracted from preserved remains. This idea has been around for decades and is already used in agriculture for resurrecting different varieties of domesticated species. However, the advent of new reproductive and genetic technologies has both increased the potential of scientists to recreate extinct species and public interest in this possibility. Credible examples of this form of "return" are few but we wonder how many conservation scholars would wager 1,000 euros that mammoth-like creatures born from mammoth DNA inserted into an elephant egg will never be created.

Ecological extinction (Table 1, Figure 1D) is the only category in our typology with an existing and widely accepted definition and refers to species that are no longer found in the wild or occur in densities so low that it "no longer interacts significantly with other species" (Estes et al. 1989, p 253). Ecological extinction can be

Table 1 Typology and definitions of extinction

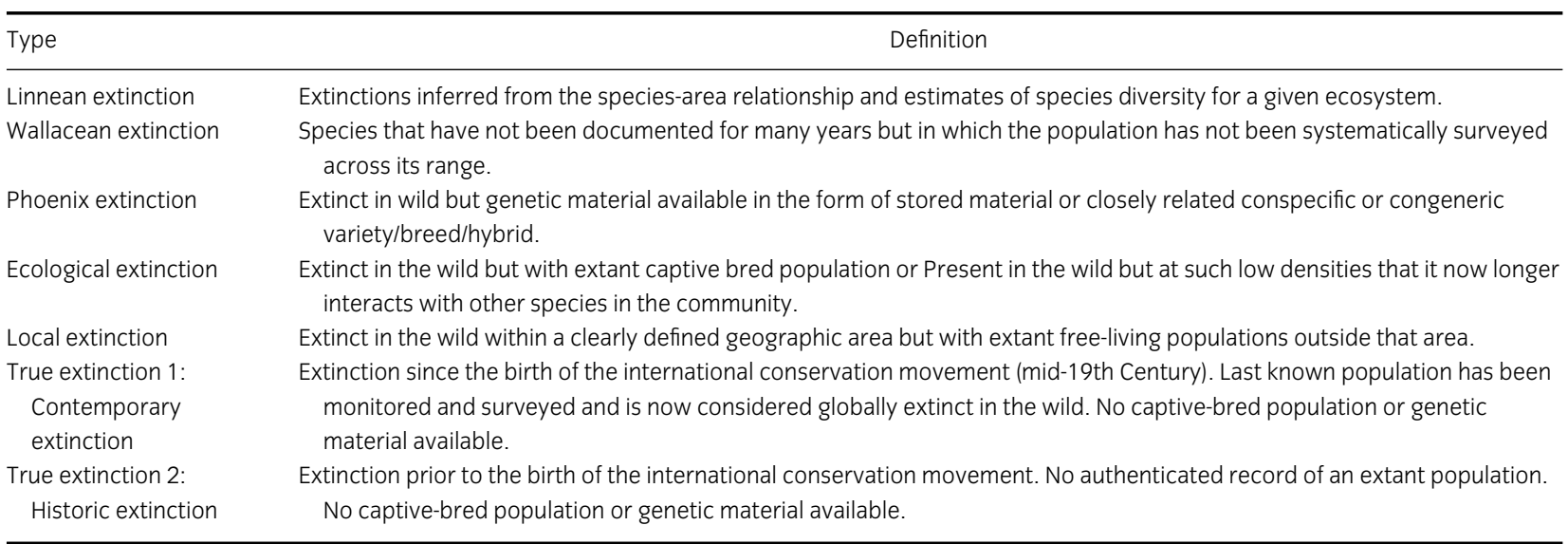


a.

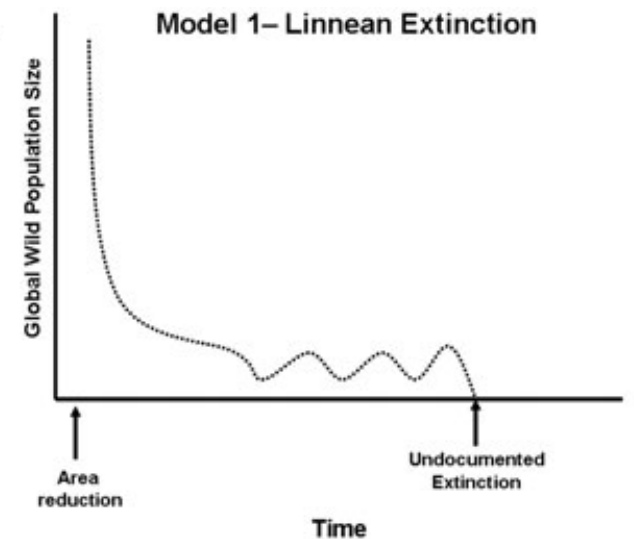

c.

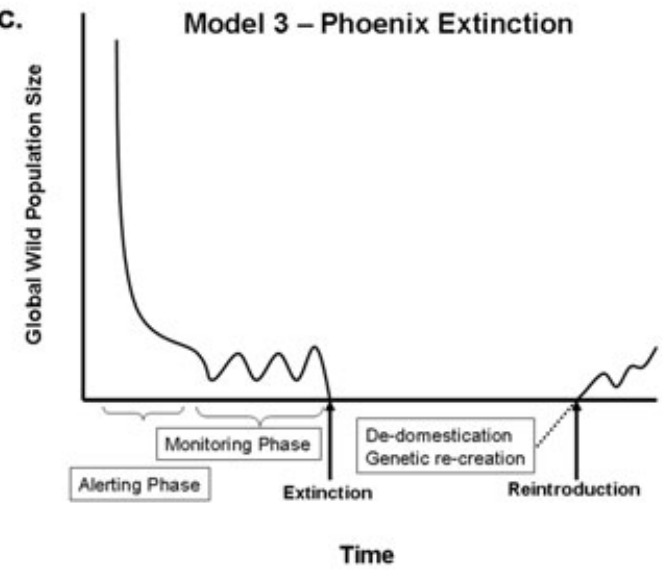

e.

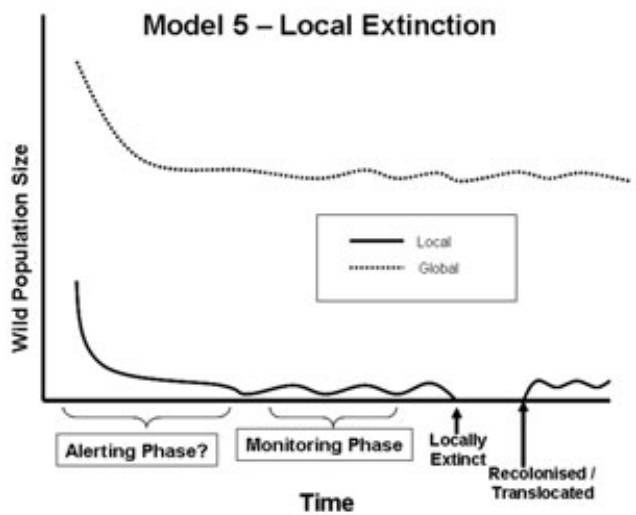

b.

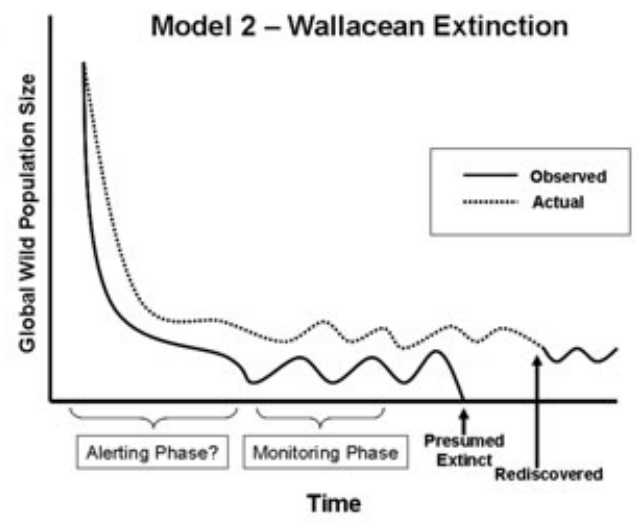

d.

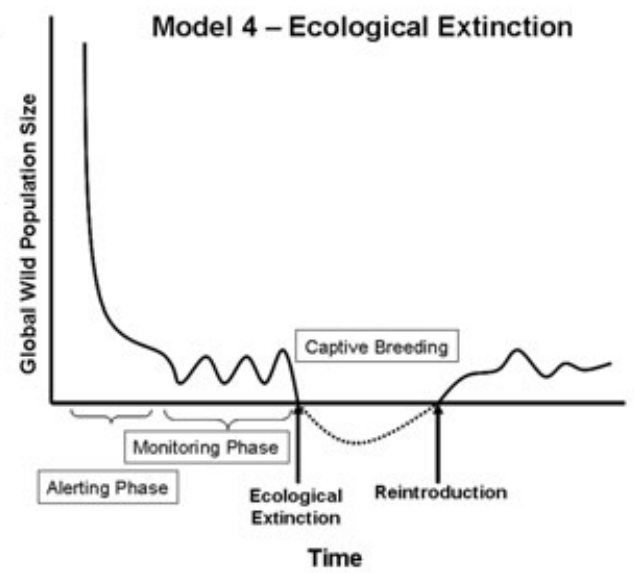

f.

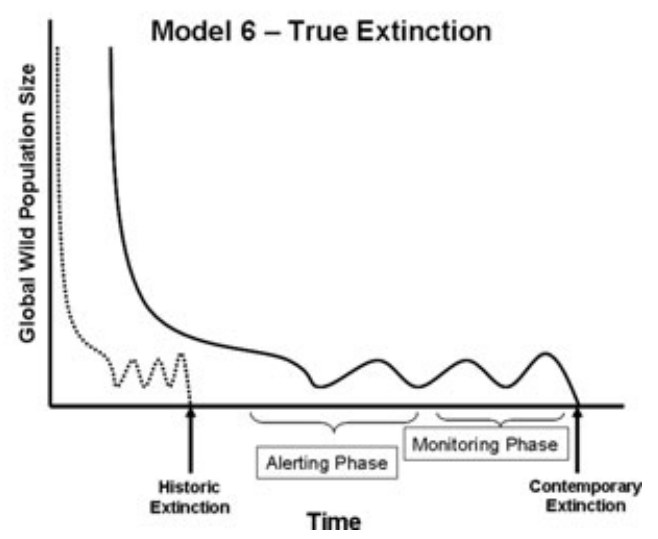

Figure 1 The typology and biocultural context of extinction: (a) Linnean extinction; (b) Wallacean extinction; (c) Ecological extinction; (d) Phoenix extinction; (e) Local extinction; and (f) True extinction (contemporary and historic).

alternatively defined as the avoidance of extinction enabled by captive-breeding programmes.

Our fifth category is local extinction, or "extirpation" (Table 1, Figure 1E), which we define as species that have disappeared from a clearly delimited geographic area (often relating to a geographical or physical boundary) but with extant, free-living populations outside that area.
Though often lacking global conservation implications these extinctions can shape national or regional conservation policy and mobilize public support for conservation.

Our final category is "true" extinction (Table 1, Figure $1 F$ ) in the sense that there is no reasonable doubt that the last population is extinct and that no captive 
population or genetic material exists. However, because the mobilizing power of such extinctions is created in part by the time it went extinct we recognize two distinct forms: contemporary extinctions and historic extinctions. We take the birth of the modern conservation movement in the mid 19th century to define contemporary because after this point the issues and solutions surrounding extinction became public (see next section). The most high profile, recent example of contemporary extinction is the final demise of the Yangtze River dolphin, or baiji (Lipotes vexillifer), whose disappearance was effectively confirmed ${ }^{1}$ after extensive surveys in November and December 2006 (Turvey et al. 2007). The baiji arguably missed entering the ecological extinction category because extensive debates among the conservation community and several high-profile international workshops failed to result in an ex-situ baiji recovery program.

\section{The agency of extinction in conservation}

Species extinction is a powerful cultural term in many societies because it can resonate with feelings deep in the human psyche. For example, Linnaean extinctions compound anxieties about the instrumental consequences of human-induced change to ecological systems, Wallacean extinctions resonate with desires for search and discovery, and ecological extinctions provide an opportunity to combine our predilections for animal husbandry and technology. Finally, historic extinctions may instill feelings of awe (dinosaurs, giant ground sloth) whilst contemporary extinctions add a sense of personal loss (thylacine), and perhaps even moral shame (Ivory-Billed Woodpecker).

The repetition and reinforcement of the meanings of extinction over successive generations and their alignment with new issues, technologies, artistic movements, social values, and so forth, creates powerful cultural narratives and practices that frame extinction as something societies should strive to avoid (or at least, minimize). There is a distinct geographic context to the mobilizing power of extinction that is deeply intertwined with national histories. For example, extinction may trigger feelings of guilt or loss among certain societal groups of predominantly European descent in New Zealand, Australia, and North America because it resonates with accounts of colonial brutality towards native peoples and/or notions of a lost Eden defiled by past rapaciousness. This may also help explain why there has been so much debate in these countries surrounding the hypothesis that early humans were responsible for the extinction of Pleistocene

\footnotetext{
${ }^{1}$ There has been 1 unconfirmed sighting of a baiji since this survey took place - http://www.baiji.org
}

megafauna (Martin 1967) despite the evidence suggesting that humans were probably only a single element in a complex web of inter-related factors driving the decline of populations (Grayson \& Meltzer 2003; Koch \& Barnosky 2006). In contrast, extinction may have far less resonance to many people living in countries where there has been a recent history of agricultural settlement and expansion into natural areas with minimal representation of natural limits in public discourse.

Our typology of extinction recognizes that different meanings open or enable entry to different governance spaces thereby enabling a more nuanced and sophisticated examination of conservation advocacy. Conservation scientists and non-government organizations (NGOs) have successfully used the Linnean meaning of extinction to attract the attention of the inter-state polity. The startling figures generated in support of the notion of a sixth mass extinction (Pimm \& Brooks 1997) bridge easily with political and bureaucratic worries about economic and social instability and the proposed macroscale solutions (for example, reducing deforestation, wetland destruction, and pollution control) and easily align with natural resource policy discourses favored by intergovernmental agencies.

Linnean extinctions are also especially prone to exaggeration, misrepresentation, and indiscriminate use in conservation advocacy. Leading conservation scientists such as Norman Myers have admitted to providing high estimates of extinction to put them onto scientific and political agendas ${ }^{2}$, while others publicly condone misrepresentation if it gets the message across (Hannah $\delta$ Phillips 2004). One of the World's highest-profile conservation organizations, Conservation International, has a constantly running extinction "clock" 3 which has racked up over 26,000 extinctions in the 6 months taken to complete this essay! This raises two important questions: (1) could uncritical use of Linnean extinction damage the credibility of the global conservation movement among scientists and policy makers, and (2) is it ethical to communicate exaggerated uncertainty to public constituencies (Ladle et al. 2004, 2005)?

Wallacean extinctions have a distinctly different type of policy power because they involve named species and localities that inspire action. They support NGO communication strategies by providing a steady stream of "good news" stories. The recent discovery of "more than 3,000 critically endangered Sociable Lapwings" (BirdLife International 2007) illustrates the enduring media appeal of the redemptive connotations embodied in the "Feared

\footnotetext{
${ }^{2}$ Www.gristmagazine.com/grist/books/myers121201.asp

${ }^{3}$ www.conservation.org/act/get_involved/Pages/stoptheclock. $\operatorname{aspx}$
} 
doomed but new hope following the discovery of. .." story line. Interestingly these good news stories often happily coexist with the doom-laden narratives about the specter of impending mass extinction.

However, Wallacean extinctions can also introduce important inefficiencies and injustices into conservation policy. For example, Gurney's pitta (Pitta gurneyi) was about to be declared extinct in 1986 when a tiny population was discovered in southern Thailand. This led to calls for "major initiatives" (Collar et al. 1986) and the investment of $\$ 400,000$ from bilateral donors in initiatives to conserve a remnant of lowland forest where the remaining population was located (R. Grimmet, personal commmunication). Subsequent surveys during 2003 in neighboring southern Myanmar found populations in excess of 3000 (Eames et al. 2005) of this "critically endangered" species described two years earlier as having "one of the lowest known populations of... any animal species on the planet" (BirdLife International 2001, p 1,895). Similarly, in East Indonesia inadequate biogeographical knowledge lead to the Tanimbar corella (Cacatua goffini), an agricultural pest, being listed as endangered and placed on the Convention on International Trade in Endangered Species of Wild Fauna and Flora (CITES) Appendix 1 (a list of species "threatened with extinction") leading to the curtailment of legal trade and the loss of an important supplemental income for the poor farmers affected by crop depredation from corellas (Jepson, 2003).

Phoenix extinctions, although perhaps the least discussed in the contemporary conservation literature, may be ultimately the most important in terms of ensuring the future impact of conservation. This is because the rebirth or re-emergence of an extinct species combines hope and vision whilst at the same time challenging some of the fundamental precepts of the global conservation movement. The creation of the Oootvaarderplassen reserve populated by Auroch and Tarpan replicates in Holland, has among other things, contributed to the creation of a vast infrastructure of ecological corridors across the country, stimulated a vigorous public debate on the nature of the relationship between humans and wild animals and is laying the foundation for a new paradigm of "open" reserve management (Sutherland 2002). This debate centered on the efforts of animal welfare lobbies to invoke laws on domestic animals to get injunctions against allowing wild horses and the Auroch replicate to starve. The counterargument put forward by the conservationists was that death through starvation was a natural process in the absence of predators.

The worldwide publicity surrounding attempts by Russian scientists to recreate the "lost" tundra habitat of the mammoth (known as the "Pleistocene Park" project) in
Siberia (Zimov 2005) illustrates the easy alignment of this conservation approach with pubic appetites for science fiction. As such, Phoenix extinctions offer an attractive alternative focus to doom-laden threats of mass extinction and promote mass interest and debate that keeps the conservation community responsive to changing social trends. It is perhaps not surprising that interest in re-wilding is therefore growing between wealthy philanthropist and landowners. The potential drawback is that Phoenix extinctions introduce considerable uncertainty into traditional assumptions regarding the "finality" of extinction as exhorted in WWF's famous slogan "extinction is forever".

Ecological extinctions clearly align with the interests of zoological gardens because they provide an outlet and legitimation for their operations. In turn, these facilities bring conservation, and endangered and exotic species, into urban culture and create links between cities and conservation sites around the world, effectively globalizing conservation culture. In a more general sense, all categories of extinction are interwoven into cultural stories and myths that contribute to the creation or reinforcement of collective identities that may lead to avoided extinction becoming a local and national cause (for example, tiger, panda, Californian condor, etc.). In this respect, understanding the cultural significance of extinction also requires that researchers adopt a historical perspective on societal understandings of extinction, or at the minimum, investigate changing spatial and temporal perspectives on animal-human relations (for example, Carruthers 2005).

\section{Turning theory into practice}

Modern conservation practice has remained largely fixated on the deterministic causes of population decline and the stochastic and tenuous nature of small populations in situ. We argue that conservationists have largely ignored the fact that once a species is identified as being at risk of extinction or declared extinct, it is subject to strong cultural forces that create the context for successful conservation (or otherwise) and of which conservationists themselves are an integral part. In other words, we have models of extinction that omit a major causal agent, namely, the behavior of conservationists, conservation organizations, and other societal actors. The influences of these actors may have positive consequences for a species, such as successful conservation interventions, but may also be negative. For example, Courchamp et al. (2006) recently demonstrated that rarity may increase the desirability and economic value of exploited species thereby pushing some declining species further down into an extinction vortex. 
When a species is identified at being at risk of extinction, conservation biology becomes entangled with the social, political, and cultural dynamics of conservation acting within the species' range. In a real sense, the study of extinction risk and population recovery becomes an interdisciplinary exercise that needs to blend insights from the natural and social sciences. Extinction in this context is both a real and imagined process that interacts with human cultural frames and institutions to produce strong moral and rational reactions leading to outcomes that reduce (or sometimes increase) the probability of a taxon disappearing from a locality (or the Earth) and produces costs and benefits for those involved. Seen in this way, extinction will only be effectively minimized when scientific evidence, cultural frames, institutional frameworks, and organizational interests align.

Adopting a biocultural perspective on extinction could have profound implications for conservation practice. For a start, it requires that we make serious efforts to go beyond essential information on the ecology of a species to include its cultural profile, contemporary and historic framings of the local human-nature relationship, the influence and capacity of conservation institutions, and so on. The task is considerable. As conservationists, we currently have little understanding of many of these cultural elements and how they interact and vary across different cultures and scales.

The adoption of a biocultural framework could also be used to inform global prioritization of conservation action. Current conservation practice identifies and assesses extinction risk primarily on the basis of ecological and biogeographical information (Ricketts et al. 2005). However, assuming that success of conservation interventions will depend on the cultural context within which it occurs, we argue that a parallel assessment of the cultural framings of conservation and the politics of local conservation actors is equally important (Figure 2). Such an interdisciplinary assessment of conservation risk could be performed at multiple spatial and cultural scales and would provide a more solid basis for global prioritization.

Furthermore, we need to develop a strong evidence base for our cultural assessments, including: (1) case studies of endangered species recovery initiatives to generate the deep insights needed to stimulate new ways of thinking and thereby inform theory development; (2) analysis of the power of the concept of extinction (in its different guises) in shaping conservation regimes, including the ways it is employed by organizations to gain access to policy and resources; and (3) surveys of how knowledge and attitudes concerning extinction has developed and varies between cultures and social groups and what triggers a concern for avoiding extinctions.

\section{Conclusions}

Minimizing extinctions is considered by many as the single-most important objective of the global conservation movement. This objective is expected to become more challenging as the effects of accelerated climatic, land-use, and social change impact on ecosystems, and as global monitoring efforts fill knowledge gaps relating to species identities and distributions. By "unpacking"

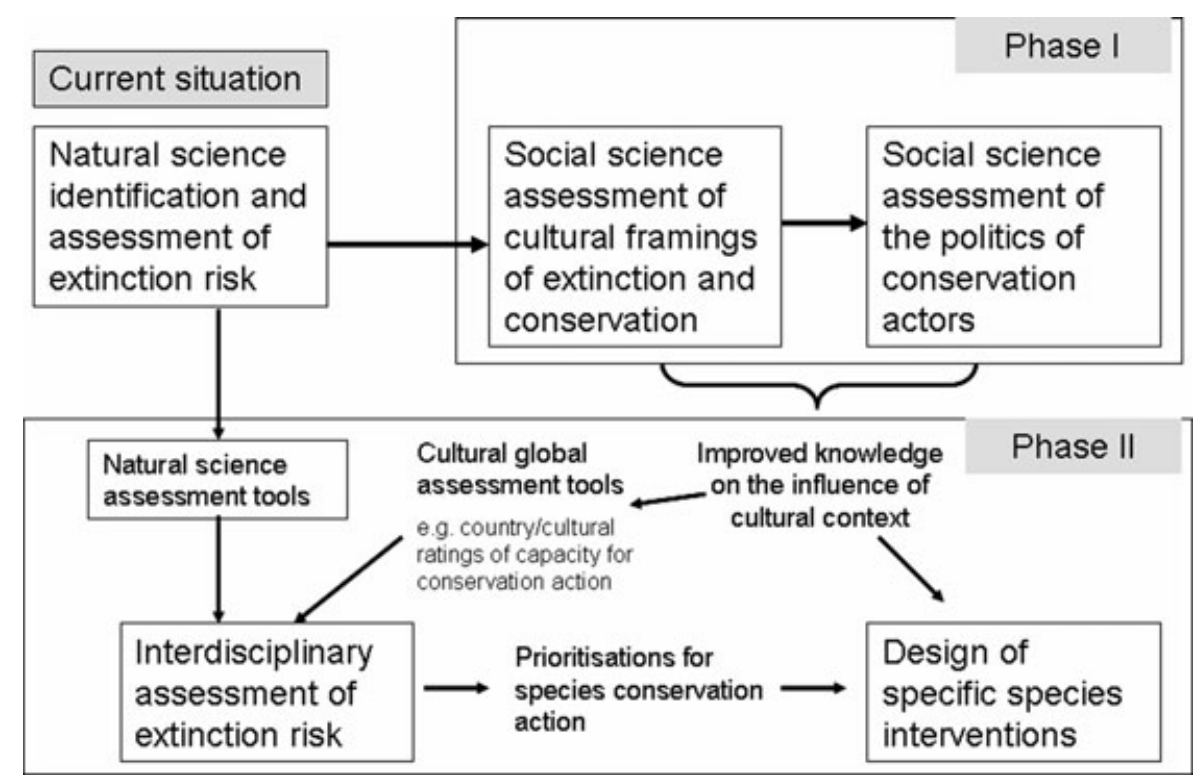

Figure 2 Proposed protocol for a phased implementation of an applied biocultural theory of avoided extinction to improve prioritization procedures. 
extinction into six types we offer a starting point for developing a biocultural theory of avoided extinction that can provide a stronger basis for successful policy and practice.

Turvey et al. (2007) noted at the end of their report on the ultimate demise of the baiji, "species cannot be expected to save themselves". To this we would add that biologists alone cannot be expected to save species from going extinct. We need to engage social anthropologists, historians, political geographers, environmental psychologists, and others in the cause. While this call to action may not be unique (cf. Brosius 2006) we hope that we have provided a conceptual and linguistic framework on which a more productive engagement can now be constructed.

\section{Acknowledgments}

We thank the following people for helping us develop the ideas and for commenting on the article: Rob Whittaker, Adrian Newton, Andrew Barry, Steve Jennings, Jamie Lorimer, Susanne Schmitt, Bill Adams, Kostas Triantis, and one anonymous referee. Special thanks to Dan Brockington for an enormously helpful and insightful review of the essay.

\section{References}

BirdLife International (2001). Threatened birds of Asia: the BirdLife International Red Data Book. BirdLife International, Cambridge.

Birdlife International (2007) Largest flock for 100 years: Sociable Lapwing lives up to its name. Available at: http://www. birdlife.org/news/news/2007/10/lapwing_superflock.html. Posted 19/10/2007. Accessed 21/11/2007.

Brosius, J.P. (2006) Common ground between anthropology and conservation biology. Conserv Biol 20, 683-685.

Carruthers, J. (2005) changing perspectives on wildlife in Southern Africa, c. 1840 to c. 1914. Soc Anim 13, 183199.

Caughley, G. (1994) Directions in conservation biology. $J$ Anim Ecol 63, 215-244.

Collar, N.J., Round P.D., Wells D.R. (1986) The past and future of Gurney's Pitta. Forktail 1, 29-51.

Courchamp, F., Angulo E., Rivalan P. et al. (2006) Rarity value and species extinction: the anthropogenic Allee effect. PLoS Biol 4, e415. doi:10.1371/journal.pbio. 0040415.

Eames, J.C., Hla H., Leimgruber P. et al. (2005) The rediscovery of Gurney's Pitta Pitta gurneyi in Myanmar and an estimate of its population size based on remaining forest cover. Bird Conserv Int 15, 3-26.

Estes, J.A., Duggins D.O., Rathbun G.B. (1989) The ecology of extinctions in kelp forest communities. Conserv Biol 3, 252-264.

Fagan, W.F., Holmes E.E. (2006) Quantifying the extinction vortex. Ecol Lett 9, 51-60.

Freese, C.H. Aune K.E., Boyd D.P. et al. (2007) Second chance for the plains bison. Biol Conserv 136, 175-184.

Gilpin, M.E., Soulé M.E. (1986) Minimum viable populations: process of extinction. Pages 19-34 in M.E. Soulé, editor. Conservation biology: the science of scarcity and diversity. Sinauer Associates, Sunderland, Mass.

Grayson, D.K., Meltzer D.J. (2003) A requiem for North American overkill. J Archaeol Sci 30, 585-593.

Hannah, L., Phillips B. (2004) Extinction-risk coverage is worth inaccuracies. Nature 430, 141.

IUCN SSC (1994) Categories and criteria version 2.3.

Available at:

http://www.iucnredlist.org/info/categories_criterial 994 Accessed December 2007.

IUCN SSC (2001) Categories and criteria version 3.1.

Available at:

http://www.iucnredlist.org/info/categories_criteria2001 Accessed December 2007.

Jepson, P. (2003) The need for a better understanding of context when applying CITES regulations: the case of an Indonesian parrot-Tanimbar corella. Pages 153-162 in S. Olfield, editor. The trade in wildlife: regulation for conservation. Earthscan, London, UK.

Koch, P.L., Barnosky A.D. (2006) Late quaternary extinctions: state of the debate. Ann Rev Ecol Syst 37, 215-250.

Ladle, R.J., Jepson P., Araujo M.B., Whittaker R.J. (2004) Dangers of crying wolf over risk of extinctions. Nature $\mathbf{4 8 2}$, 799.

Ladle, R.J., Jepson P., Whittaker R.J. (2005) Scientists and the media: the struggle for legitimacy in climate change and conservation science. Interdiscip Sci Rev 30, 231-240.

Lomolino, M.V. (2004) Conservation biogeography. Pages 293-96 in M.V. Lomolino, L.R. Heaney, editors. Frontiers of biogeography: new directions in the geography of nature. Sinauer, Sunderland, Mass.

Mace, G.M., Lande R. (1991) Assessing extinction threats: toward a re-evaluation of IUCN threatened species categories. Conserv Biol 5, 148-157.

Martin, P.S. (1967) Prehistoric overkill. Pages 75-120 in P.S. Martin, H.E. Wright Jr., editors. Pleistocene extinctions: the search for a cause. Yale University Press, New Haven, Conn.

Norris, K. (2004) Managing threatened species: the ecological toolbox, evolutionary theory end declining population paradigm. J Appl Ecol 41, 413-426.

Pimm, S.L., Brooks T.M. (1997) The sixth extinction. How large, where, and when? in P.H. Raven, T. Williams, editors. Nature and human society. The quest for a sustainable world. National Academy Press, Washington D.C.

Ricketts, T.H., Dinerstein E., Boucher T. et al. (2005) Pinpointing and preventing imminent extinctions. Proc Nat Acad Sci U S A 102, 18497-18501. 
Sutherland, W.J. (2002) Openness in management. Nature 418, 834-835

Turvey, S.T., Pitman R.L., Taylor B.L. et al. (2007) First human-caused extinction of a cetacean species? Biol Lett $\mathbf{3}$, 537-540.

Wilson, E.O. (1991) The Diversity of Life. Harvard University Press, Cambridge, Mass.
Whittaker, R.J., Araújo M.B., Jepson P., Ladle R.J., Watson J.E.M., Willis K.J. (2005) Conservation biogeography: assessment and prospect. Divers Distrib 11, 3-23.

Zimov, S.A. (2005) Pleistocene park: return of the mammoth's ecosystem. Science 308, 796.

Editor: Paige West 